\title{
Sewer Ventilation Modeling
}

\section{Scott A. Lowe}

Manhattan College, Riverdale, New York.

\begin{abstract}
A model of sewer ventilation was developed using a relationship between the water and air velocities. SWMM hydraulic output was used to compute the water velocity and flow depth. The flow depth is used to compute the headspace area. In conjunction with the calculated air velocity this allows the air flow rate to be computed. The model was calibrated and validated using five studies that included data from collection systems in four cities, plus two experimental setups. The results showed that the model

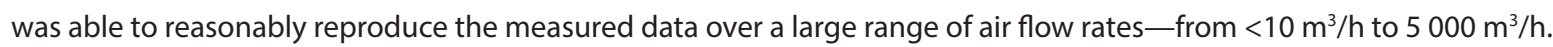

\section{Introduction}

In the design of sewer systems (specifically sanitary sewers at this point, since combined systems are no longer constructed) there is typically little design attention paid to air movement. Yet air movement is one of the determining factors in odour and corrosion problems (Koe and Brady 1986). Odour problems can be a major issue for system owners and can be difficult to fix (e.g. City of Los Angeles 2011). Pipe corrosion causes huge maintenance issues and expense (e.g. Sydney et al. 1996).

The calculation of corrosion and odours in sewer systems is a two part process (Boon 1995). The first part is the calculation of air flow rates. The second part is the estimation of concentrations, usually hydrogen sulfide (Reid and Imel 1956). This paper deals only with the air flow rate calculation.

An overview of the mechanisms effecting the air movement in sewers is given by Edwini-Bonsu and Steffler (2006) and Lowe (2016). The main mechanism is friction drag between the air and water, causing the air to move in the same direction as the water. However there are many complicating factors that make the computation of sewer ventilation rates challenging. Some of these include:

1. The effect of drop structures. These can draw air into the system as the water free falls to a lower elevation; or act as an air flow bottleneck; or act as a complete air flow block if the bottom of the structure is inundated (Falvey 1980).

2. Buoyancy effects: the air in sewers tends to be warmer and have more moisture than the ambient air, especially in winter (Yongsiri et al. 2004). This makes sewer headspace air less dense than the ambient air. Although counter-intuitive, air with a higher water content is actually less dense, as the molecular weight of water $(18 \mathrm{~g} / \mathrm{mol})$ is less than either $\mathrm{N}_{2}$ or $\mathrm{O}_{2}(28 \mathrm{~g} / \mathrm{mol}$ and $32 \mathrm{~g} / \mathrm{mol}$ respectively). This creates the potential for air exchange, as denser ambient air enters the system and displaces the lighter headspace air. This is a particular issue for combined sewer overflow (CSO) storage tunnels that sit empty most of the time (Schultz et al. 2012).

3. CSO storage tunnels that are designed to be fillable create unique issues as they have no headspace.

This means that all the air flowing toward them must be vented (Lautenbach et al. 2012). Additionally, as water fills the tunnel that volume of air must also be displaced.

4. The presence of siphons. At the head end of siphons all the air must be vented as there is no headspace in the siphon pipe.

5. Air compressibility. Unlike water, which is assumed to be incompressible in typical sewer calculations, air can be compressed. This means simple volumetric flow balances may need adjustment.

6. Air pressure. Air, like all fluids, moves from high pressure to low pressure. If the air pressure at all points in a system was known then the air flow rates in the system could be computed with reasonable accuracy. If sewer systems were closed systems this might be possible.

However sewer systems have thousands of connections to the ambient air; via manholes, for example. Each manhole presents a unique air pressure boundary condition. Studies have shown the importance of pressure variations at manholes in effecting local system air flows (WERF 2009; Parker and Ryan 2001). At present there are no methods available to reliably predict manhole pressure variations.

So while recognizing some of the complicating factors listed above, it is still important to realize that friction induced air flow from the water will still be the main mechanism. It is therefore this phenomenon that is the focus of this paper. Specifically

Lowe, Scott A. 2017. Sewer Ventilation Modeling. Journal of Water Management Modeling 25:C415. https://doi.org/10.14796/JWMM.C415 ๑ C CHI 2017. www.chijournal.org ISSN 2292-6062. 
this paper looks at using the USEPA Storm Water Management Model (SWMM) to provide the key hydraulic inputs necessary for the air flow rate calculation.

\section{Model Development and Calibration}

The main objective of the study was to develop a model to compute sewer air flow rates based on SWMM hydraulic output. The first step was to develop a relationship between the sewer hydraulics and air flow based on actual field measurements. This can be thought of as the model calibration. Once calibrated the model could then be validated against other data from different systems.

The data used for model calibration was based on an extensive study by Parker and Ryan (2001). The study was conducted over $11 \mathrm{~km}$ of the Ottawa-Carleton sanitary sewer system with pipe sizes ranging from $0.61 \mathrm{~m}$ to $2.1 \mathrm{~m}$ ( $24 \mathrm{in}$. to $84 \mathrm{in}$.). This study was chosen as it spanned a large range of both water and air flow rates. Water flows at the head end of the system were $0.09 \mathrm{~m}^{3} / \mathrm{s}$ and increased to $0.71 \mathrm{~m}^{3} / \mathrm{s}$ by the last reach. The physical characteristics of the system are summarized in Table 1.

Table 1 Physical characteristics of Ottawa-Carleton sanitary sewer system.

\begin{tabular}{ccccc}
\hline Segment & Diameter $(\mathrm{m})$ & Length $(\mathrm{m})$ & Distance $(\mathrm{m})$ & Slope $(\%)$ \\
\hline 1 & 0.61 & 1189 & 1189 & $0.007-0.67$ \\
2 & 0.69 & 643 & 1832 & $0.09-0.94$ \\
3 & 0.76 & 532 & 2364 & $0.001-0.77$ \\
4 & 1.40 & 518 & 2882 & $0.04-0.48$ \\
5 & 1.20 & 1765 & 4647 & $0.001-0.83$ \\
6 & 1.40 & 2788 & 7435 & $0.001-0.65$ \\
7 & 1.50 & 1294 & 8729 & $0.006-0.32$ \\
8 & 2.00 & 1511 & 10240 & $0.001-0.44$ \\
9 & 2.10 & 808 & 11048 & $0.001-0.7$ \\
\hline
\end{tabular}

A SWMM model of the system was developed. The SWMM-computed water velocities were plotted against the measured air velocities as shown in Figure 1. Air velocities were not measured in pipe segments 2 and 4 . The best relationship between the air and water velocities was given by a second order polynomial:

$$
V_{\text {air }}=0.242 V_{w}-0.032 V_{w}^{2}
$$

where:

$$
\begin{aligned}
& V_{\text {air }}=\text { air velocity in } \mathrm{m} / \mathrm{s} \text {, and } \\
& V_{w}=\text { average water velocity in } \mathrm{m} / \mathrm{s} .
\end{aligned}
$$

As expected with such a limited and scattered dataset the correlation is modest $\left(R^{2}=0.62\right)$. This, however, is typical of field sewer ventilation data. The real question was how air flow rates based on this relation would compare.

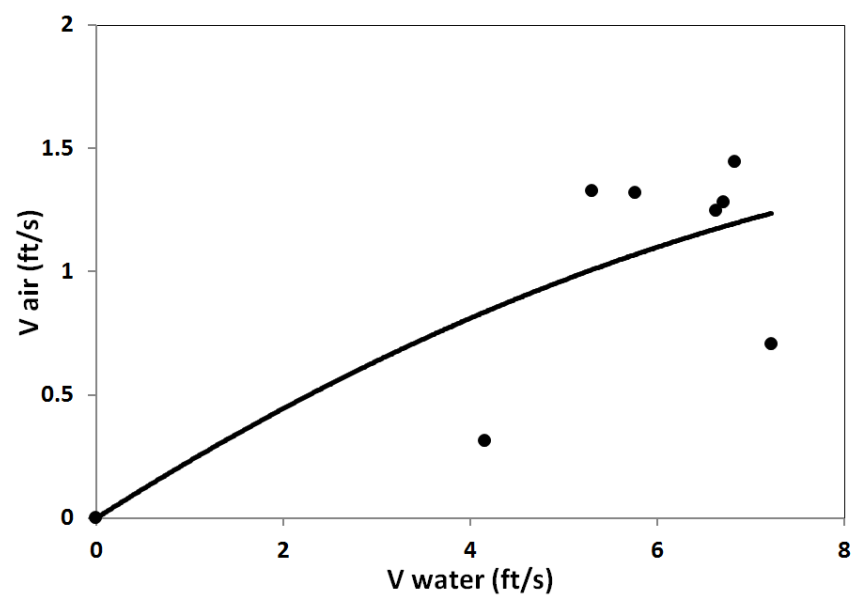

Figure 1 Relationship between air and water velocity.

The SWMM output also contains the flow depth in each pipe. This can be used to compute the cross sectional area of the flow in each pipe. This allows the headspace area to be computed. Multiplying headspace area by the air velocity estimated in Equation 1 gives the estimated air flow rate. The modeled and measured results are given in Figure 2 .

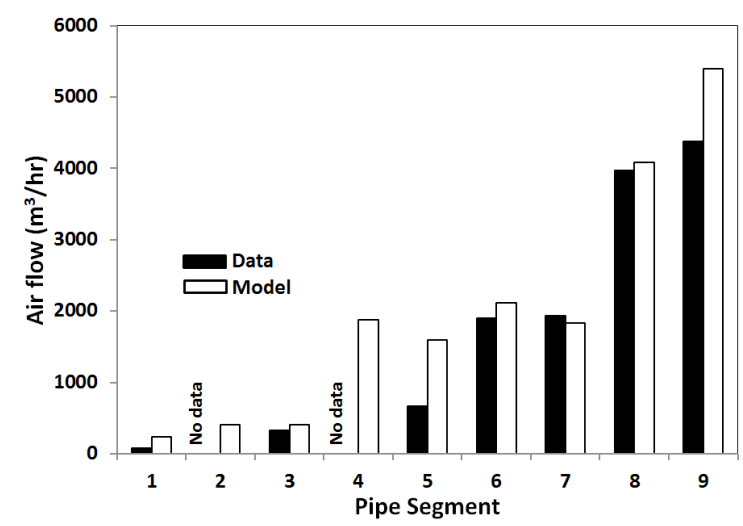

Figure 2 Modeled air flow for the Ottawa-Carleton sewer system.

The results shown in Figure 2 look surprisingly good given the modest air to water velocity relationship they are based on. Figure 3 shows the percentage error (\%error), calculated as:

$$
\text { \%error }=\frac{\text { Modeled }- \text { Measured }}{\text { Measured }}
$$

The formulation was set up this way so that a negative value indicates the model underpredicted, and a positive value indicates the model overpredicted. The results are shown in Figure 3.

This brings up the question: what exactly is a good result and how should the results shown in Figures 2 and 3 be interpreted?

Perhaps the first item to discuss in relation to this question is expectations. For all of the reasons mentioned previously 
in Section 1, it is not realistic to expect that airflow rates will ever be predicted with the accuracy of the system hydraulics. In discussions with engineers there seemed to be a general notion that any prediction within a factor of two would be considered good, considering that there is essentially no predictive capability available at all at the present time. This would be an error of $\pm 100 \%$.

In a sewer ventilation study conducted by the Water Environmental Research Foundation (now the Water Environment \& Reuse Federation, WERF 2009), numerical models were compared to measured results. The best model was an empirical model which had an average error of $103 \%$. The average error from Figure 3 is $61 \%$, and the median error is $23 \%$. So in the context of WERF study, and the rule of thumb mentioned above, this seems like a good result. However this is the model calibration-the real test of prediction is the validation stage that follows.

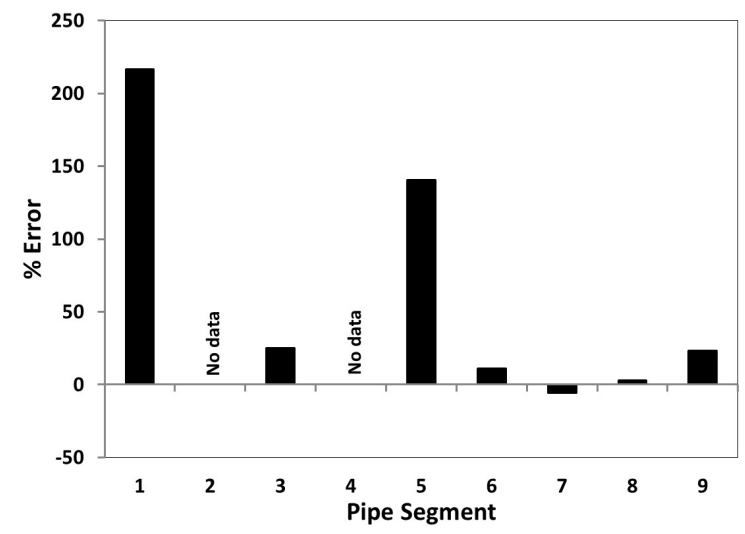

Figure 3 Model performance for the Ottawa-Carleton sewer system.

Using this as the starting point the model was then applied to other datasets to see how it compared. This was the model validation phase.

\section{Model Validation}

The model developed above was tested using data from four separate studies. The first two studies were a series of experiments. The next two used data collected from sewer systems in three cities: Seattle, Los Angeles and Toronto. Combined, these studies had air flow rates that ranged from $<10 \mathrm{~m}^{3} / \mathrm{h}$ to $>10000 \mathrm{~m}^{3} / \mathrm{h}$.

\subsection{Pescod and Price Study}

A laboratory based experimental study was conducted by Pescod and Price (1982) to examine the effect of liquid drag on air flows using a $0.3 \mathrm{~m}$ (12 in.) diameter pipe. The test details, as supplied in their paper, are given in Table 2.
Table 2 Details of Pescod and Price study.

\begin{tabular}{ccccc}
\hline Test\# & Water Depth Fraction & V water $(\mathrm{m} / \mathrm{s})$ & V air $(\mathrm{m} / \mathrm{s})$ & Q air $(\mathrm{L} / \mathrm{s})$ \\
\hline 1 & 0.5 & 0.6 & 0.2 & 7.3 \\
2 & 0.25 & 0.6 & 0.18 & 10.5 \\
3 & 0.75 & 0.6 & 0.21 & 2.97 \\
4 & 0.5 & 0.4 & 0.21 & 7.9 \\
5 & 0.75 & 0.4 & 0.17 & 2.24 \\
6 & 0.25 & 0.4 & 0.12 & 7.2 \\
7 & 0.5 & 0.2 & 0.07 & 2.6 \\
8 & 0.4 & 0.8 & 0.2 & 8.9 \\
9 & 0.38 & 0.4 & 0.11 & 5.3 \\
\hline
\end{tabular}

As with the calibration procedure, a SWMM model was set up to represent the system. SWMM results were used to compute the air flow rates. The results are shown in Figure 4. The results again look reasonable, especially considering that these air flow rates are 1 to 2 orders of magnitude less than the calibration data set.

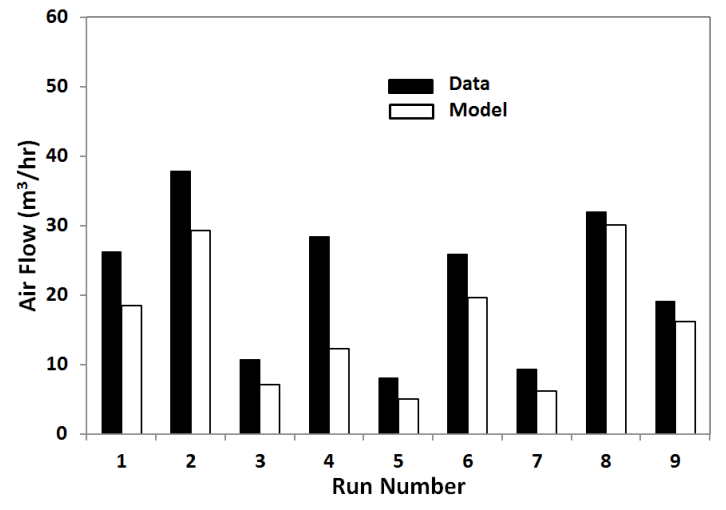

Figure 4 Modeled air flow for Pescod and Price study.

The $\%$ error is shown in Figure 5 (where possible a standard axis of $\pm 100 \%$ will be used in all error plots to facilitate direct comparisons). In this case the model underpredicted every run but only once did the error exceed $-50 \%$. The average error was $-29 \%$ and the median error was $-30 \%$.

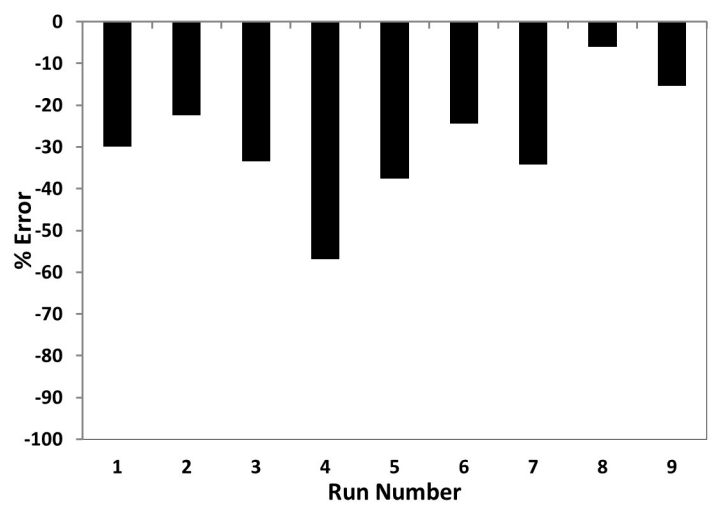

Figure 5 Model performance for Pescod and Price study.

\subsection{Koziel, Corsi and Lawler Study}

Koziel, Corsi and Lawler (2001) conducted experiments on a $61 \mathrm{~m}$ $(200 \mathrm{ft}$ ) long pipe with a diameter of $0.2 \mathrm{~m}$ (8 in.). Although the 
focus of this study was VOC emissions, air flow rates were also measured. Some of the experiments forced the air counter to the water flow. These were not modeled. Details of the experiments, as given in their paper, are given in Table 3.

Table 3 Details of Koziel et al. study.

\begin{tabular}{cccccc}
\hline Experiment & Slope (\%) & Water Depth $(\mathrm{mm})$ & V water $(\mathrm{m} / \mathrm{s})$ & V air $(\mathrm{m} / \mathrm{s})$ & Q water $(\mathrm{L} / \mathrm{s})$ \\
\hline 1 & 2 & 12.8 & 0.48 & 0.16 & 0.41 \\
2 & 2 & 25.5 & 0.75 & 0.22 & 1.76 \\
3 & 1.5 & 12.8 & 0.42 & 0.13 & 0.36 \\
4 & 1.5 & 25.7 & 0.65 & 0.21 & 1.55 \\
5 & 1 & 13.4 & 0.35 & 0.15 & 0.32 \\
6 & 1 & 25.7 & 0.53 & 0.16 & 1.27 \\
7 & 0.5 & 25.8 & 0.38 & 0.12 & 0.90 \\
8 & 0.5 & 39 & 0.48 & 0.27 & 2.11 \\
9 & 0.5 & 13.2 & 0.25 & 0.08 & 0.22 \\
10 & 0.5 & 47 & 0.54 & 0.18 & 3.02 \\
\hline
\end{tabular}

A SWMM model of the system was developed and used to calculate air flow rates. The results are shown in Figure 6 . As before the model agreement is reasonable. Also as before the flow rates are much lower than those used in the calibration.

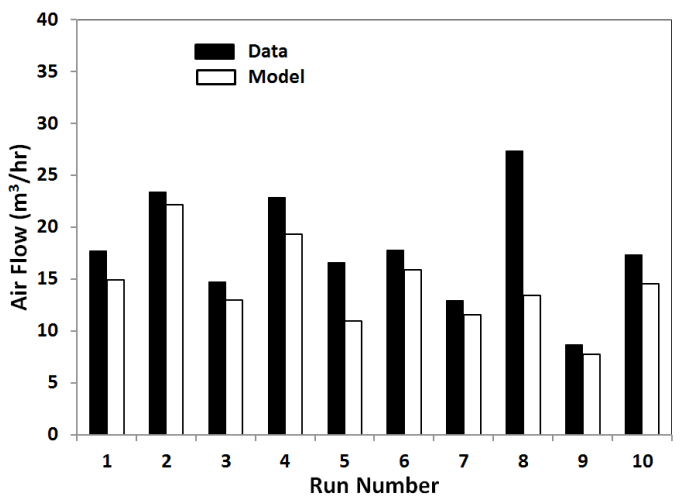

Figure 6 Modeled air flow for Koziel et al. study.

The model performance is shown in Figure 7. As with the previous case the model underpredicted every run. The maximum error was $-50 \%$. The average error was $-18 \%$ and the median error was $-14 \%$.

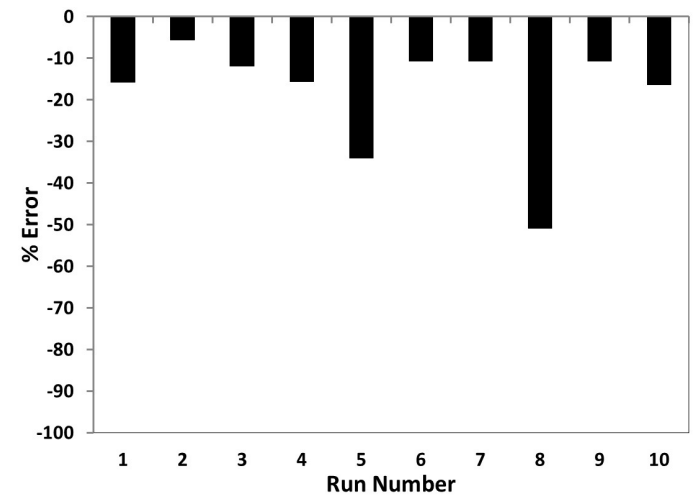

Figure 7 Model performance for Koziel et al. study.

\subsection{Los Angeles and Seattle}

The Water Environmental Research Foundation (now the Water Environment \& Reuse Foundation, WERF) conducted a series of air flow rate experiments at four locations within the King County, Washington (Seattle area) and Los Angeles County wastewater collection systems (WERF 2009). The details of the four systems, as given in the report, are in Table 4.

Table 4 Details of the WERF study.

\begin{tabular}{lcccccc}
\hline \multicolumn{1}{c}{ Location } & Pipe Type & Diameter $(\mathrm{m})$ & Length $(\mathrm{m})$ & Slope $(\%)$ & V water $(\mathrm{m} / \mathrm{s})$ & V air $(\mathrm{m} / \mathrm{s})$ \\
\hline $\begin{array}{l}\text { West Covina (LA) } \\
\text { Torrance (Seattle) }\end{array}$ & RCP & $0.84(33 \mathrm{in})$. & 220 & 0.51 & 2.11 & 0.12 \\
$\quad$ Test 1 & RCP & $1.37(54 \mathrm{in})$. & 172 & 0.047 & 0.77 & 0.22 \\
Test 2 & RCP & $1.37(54 \mathrm{in})$. & 172 & 0.047 & 0.79 & 0.14 \\
Test 3 & RCP & $1.37(54 \mathrm{in})$. & 172 & 0.047 & 0.78 & 0.26 \\
Renton (LA) & RCP & $2.44(96 \mathrm{in})$. & 278 & 0.086 & 1.38 & 0.18 \\
North Seattle & RCP & $0.61(24 \mathrm{in})$. & 128 & 0.7 & 2.10 & 0.10 \\
\hline
\end{tabular}

The SWMM based model results are shown in Figure 8. For the Torrance and Renton locations the model results look reasonable. The model overpredicts the North Seattle and West Covina locations. Both of these sites stood out in the WERF study as having large water velocities but small air velocities.

At the West Covina location there was an air flow restriction noted in the report, the cause of which was unknown. As the model has no restrictions in place it not surprising that it significantly overpredicts the flow rate.

The North Seattle location was unusual in that the upstream end of the measured reach was the end of a force main. Apparently the pump cycling caused frequent air flow reversals after the pump switched off. This reduced the net air flow rate and resulted in the small average number that is shown $\left(\sim 85 \mathrm{~m}^{3} / \mathrm{h}\right)$. Again none of this was incorporated into the model and so it is not surprising the model overpredicts the flow rate here.

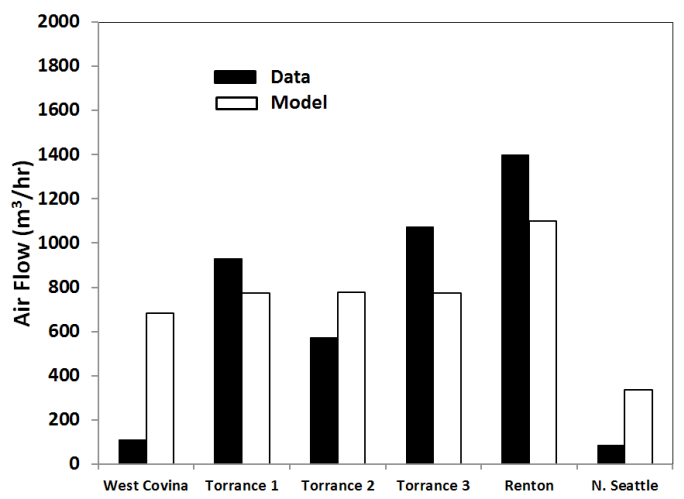

Figure 8 Modeled air flow for WERF study.

The model performance shown in Figure 9. The two outliers are noted. The other sites had good results-within $50 \%$ error. The average (absolute) and median (absolute) results for all sites was $153 \%$ and $32 \%$. If the outliers are removed the average and median results are both $25 \%$. 


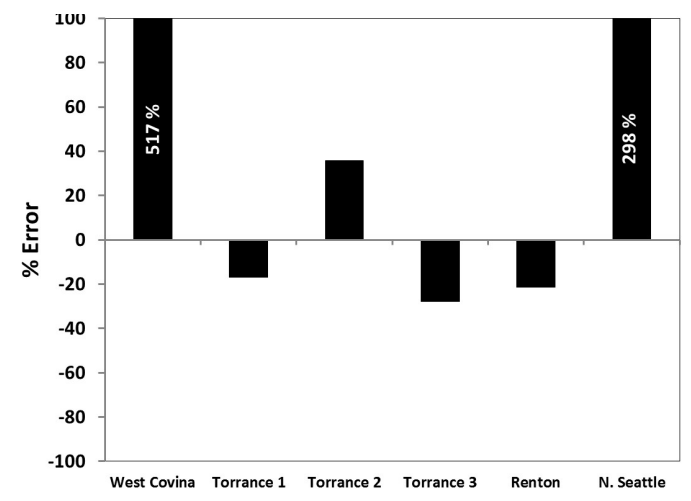

Figure 9 Model performance for WERF study.

\subsection{Toronto}

A 1995 study was conducted on a large sewer interceptor in Toronto (Quigley and Corsi 1995). The details of the system, based on their paper, are given in Table 5. The typical midday flow in the study was $0.2 \mathrm{~m}^{3} / \mathrm{s}$ and the flow depth was $20 \mathrm{~cm}$ to $25 \mathrm{~cm}$.

Table 5 Details of the Toronto sewer system.

\begin{tabular}{|c|c|c|c|}
\hline Reach & Diameter (m) & Length (m) & Slope (\%) \\
\hline 1 & 0.9 & 880 & 1.0 \\
\hline 2 & 1.1 & 115 & 0.60 \\
\hline 3 & 1.1 & 425 & 0.50 \\
\hline 4 & 1.2 & 210 & 0.25 \\
\hline
\end{tabular}

As the focus of the study was VOC emissions, the air flow rates were noted as ranges. For three sampling events that took place between $\sim 09: 00$ and 16:00 on three separate days, the air flow ranges were reported as $1300 \mathrm{~m}^{3} / \mathrm{h}$ to $1800 \mathrm{~m}^{3} / \mathrm{h}$ (day 1 ); $1300 \mathrm{~m}^{3} / \mathrm{h}$ to $2300 \mathrm{~m}^{3} / \mathrm{hr}$ (day 2); and $1300 \mathrm{~m}^{3} / \mathrm{h}$ to $1600 \mathrm{~m}^{3} / \mathrm{h}$ (day 3 ). The average of these flows and the computed model results are shown in Figure 10. There is good agreement between the modeled and measured air flow rates.

The study also noted that air was drawn into the system through manholes in reaches 1 and 2, and air was vented through manholes in reaches 3 and 4 . The ventilation model predicted the same sequence.

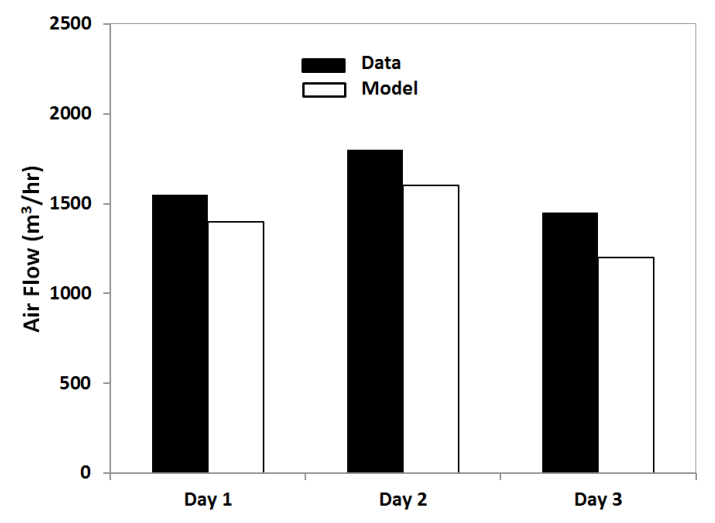

Figure 10 Modeled air flow for Toronto sewer system.
The model performance is given in Figure 11. Again the model underpredicted on each day, but was always within $20 \%$. The average and median errors are $-13 \%$ and $-11 \%$.

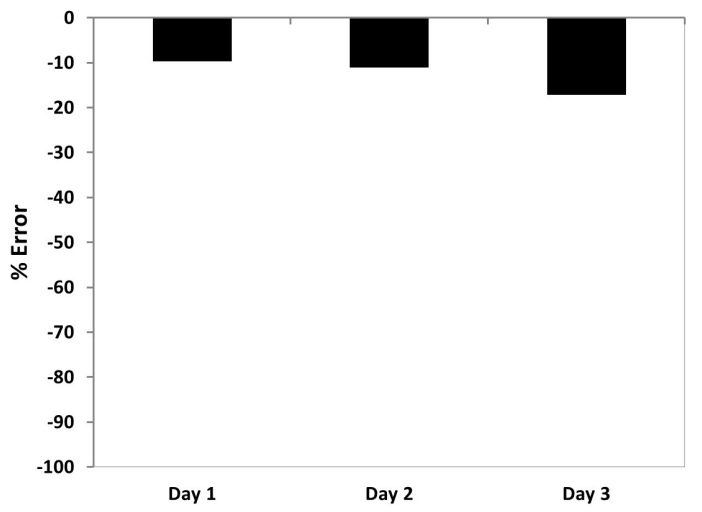

Figure 11 Model performance for Toronto sewer system.

\subsection{Summary of Calibration and Validation Re-}

\section{sults}

The results of both the calibration and validation are encouraging. The calibration and validation results showed that the model could reliably reproduce the measured air flow rates in nearly all cases. The model was able to compute values over a large range of air flow rates, from $<10 \mathrm{~m}^{3} / \mathrm{h}$ to $>5000 \mathrm{~m}^{3} / \mathrm{h}$. The results of all the model runs are shown graphically in Figures 12 and 13 below.

Figure 12 highlights the large range used in the model validation, to the point where the smaller results are not even visible on the chart. The same results are plotted on a logarithmic axis in Figure 13, where all the results can be seen more clearly.

The average error for all runs was 51\%. The median error for all runs was $22 \%$. If the two WERF sites that had issues are excluded the average and median errors are $30 \%$ and $21 \%$.

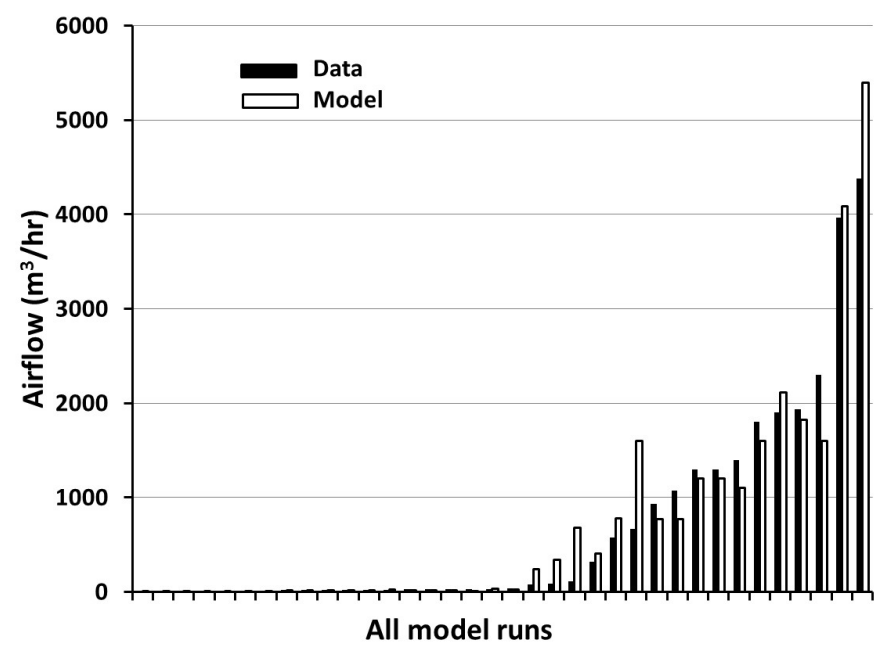

Figure 12 All model results on a linear axis. 


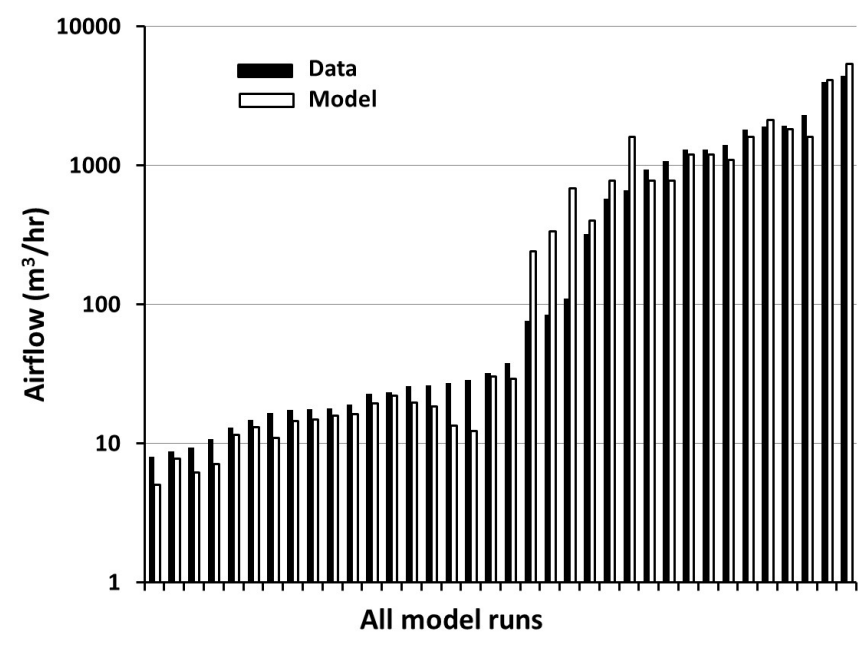

Figure 13 All model results on a logarithmic axis.

\section{Example Application}

To show how the ventilation model can be applied, an existing SWMM sanitary sewer model was used. Figure 14 below shows the SWMM layout for the sanitary sewer of a 60 lot development. The lot areas ranged from 0.2 ha to 0.6 ha ( 0.5 acres to 1.5 acres). Pipe sizes ranged from $0.2 \mathrm{~m}$ to $0.76 \mathrm{~m}$ (8 in. to $30 \mathrm{in}$.). Slopes varied from $0.25 \%$ to $3.6 \%$. Pipe $A$ is highlighted for further analysis.

In this case the inflow-infiltration (I/I) for the system was based on a small percentage of a Type II, $6 \mathrm{~h}$ design storm of $10 \mathrm{~cm}$ (4 in.) entering the system. The air flow rates at the peak system hydraulic flows are shown in Figure 15 below for various reaches. The air flow rates generally increase through the system, with increasing water velocities and increasing headspace in the larger pipes. However, from section to section there are also frequent decreases in air flow rates, reflecting local changes in slope or water velocity.

When air flow decreases from one section to the next, the excess air is vented at the nearest manhole (MH). The $\mathrm{MH}$ venting locations and rates are shown in Figure 16 below.

One advantage of using SWMM as the basis for computing air flow rates is the ability to produce a time variable analysis. An example is Pipe A that was highlighted in Figure 14 above. The response of the pipe in terms of water and air flow rates is shown in Figure 17 below. The responses are noticeably different. At the peak water flow rate the air flow actually decreases due to the lack of headspace in the pipe. This can be seen in Figure 18 below which shows the two components used to compute the air flow rate-the air velocity and the headspace area.

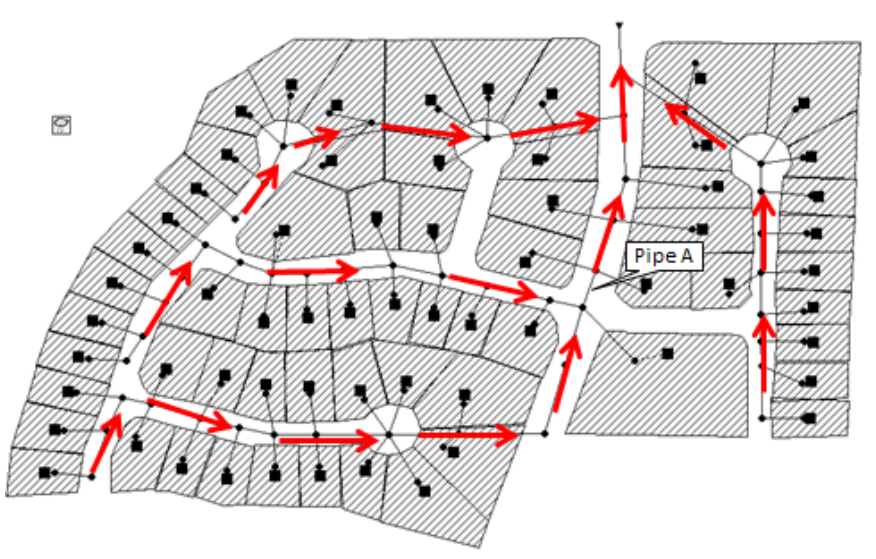

Figure 14 SWMM sanitary sewer model for a small development.

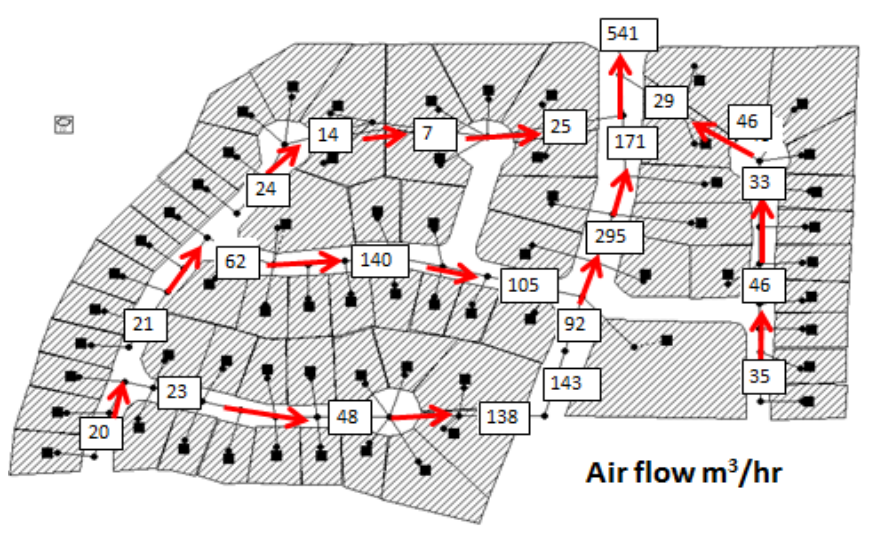

Figure 15 Modeled air flow rates at peak wet weather flow.

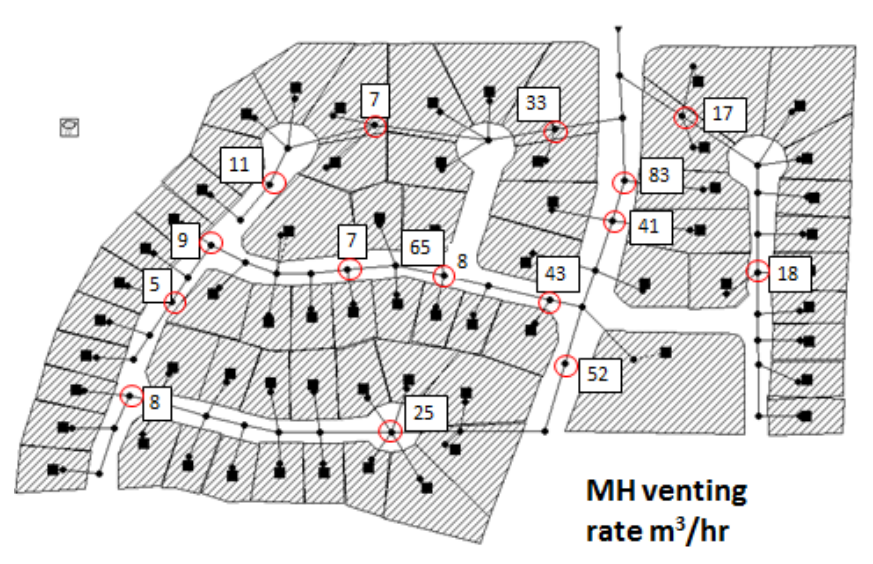

Figure 16 Modeled air flow venting locations and rates. 


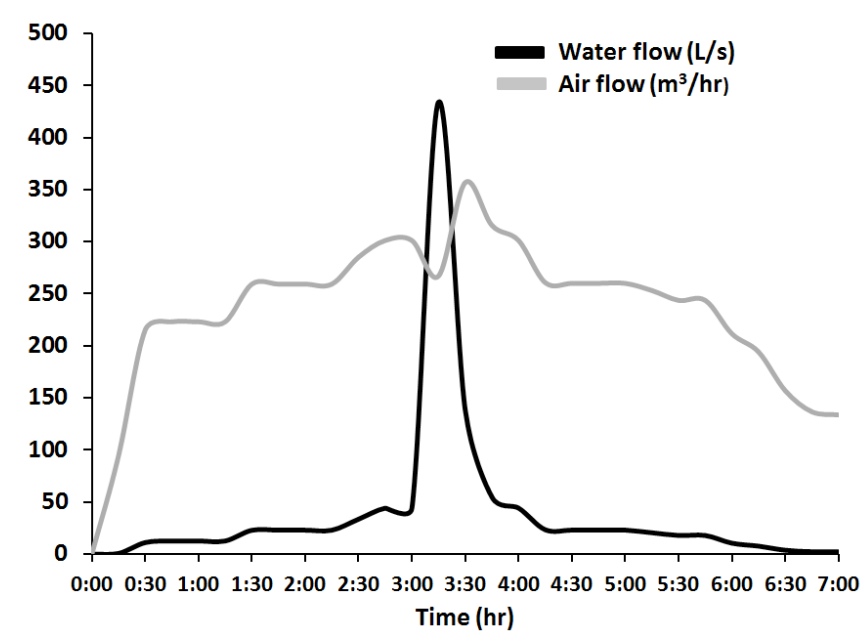

Figure 17 Time variable air and water flows in pipe A.

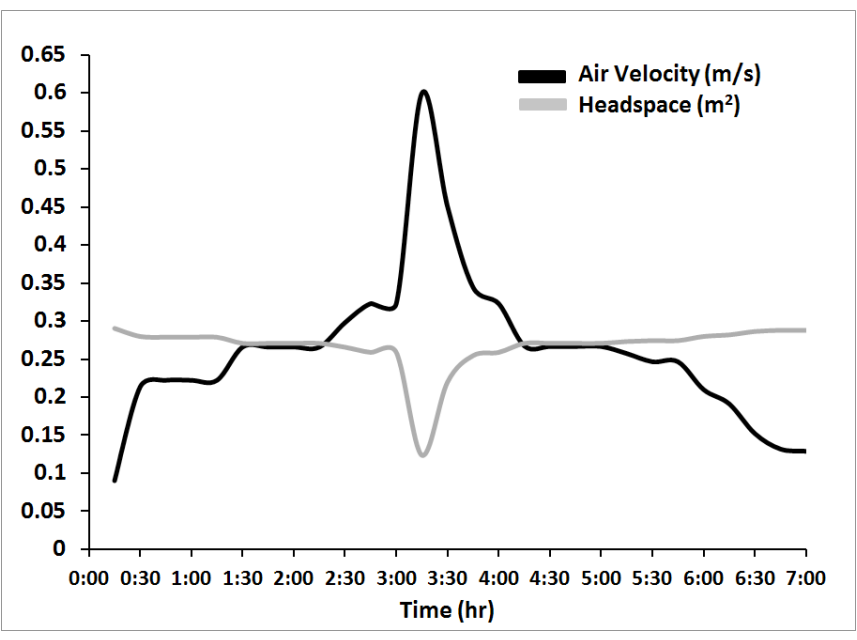

Figure 18 Air velocity and headspace in pipe A.

\section{Conclusions}

The analysis of odour or corrosion in sewer systems involves two components: air flow rates and concentrations. This paper deals with the first component, the calculation of sewer air flow rates.

A sewer ventilation model was developed using hydraulic output from the USEPA SWMM model. A relationship between water velocity and air velocity was derived based on measured data. The data was scattered and the relationship was not that strong. SWMM was used to compute the water velocity and the water depth in the pipes. The water depth allowed the headspace cross sectional area to be computed. The air velocity is found using the derived air-water velocity relationship. The air flow rate is the product of the headspace area and the air velocity.

The model was calibrated to measured system data collected in Ottawa. The calibration results were somewhat mixed across a large range of air flow rates: $100 \mathrm{~m}^{3} / \mathrm{h}$ to $5000 \mathrm{~m}^{3} / \mathrm{h}$. In five of runs the model results were within $25 \%$ of the data. In two of the runs the model results were $>100 \%$ larger than the data.

The model was then validated using four studies, two of which were experimental, and two using real sewer systems. The real systems included Los Angeles, Seattle and Toronto. The validation results were actually better than the calibration results, with the model usually with $30 \%$ of the data.

The calibration and validation results showed the model could reproduce results across a large range of air flows from $<10 \mathrm{~m}^{3} / \mathrm{h}$ to $>5000 \mathrm{~m}^{3} / \mathrm{h}$. Modeled pipes ranged in size from $0.2 \mathrm{~m}$ (8 in.) to $2.44 \mathrm{~m}$ (96 in.).

\section{References}

Boon, A. G. 1995. "Septicity in Sewers: Causes, Consequences and Containment." Water Science and Technology 31 (7): 237-53.

City of Los Angeles. 2011. Sewer Odour Control Master Plan. Technical Report prepared by the Wastewater Engineering Services Division, Bureau of Sanitation.

Edwini-Bonsu, S. and P. M. Steffler. 2006. "Dynamics of Airflow in Sewer Conduit Headspace." Journal of Hydraulic Engineering 132 (8): 791-9. https://doi.org/10.1061/(ASCE)0733-9429(2006)132:8(791).

Falvey, F. 1980. Air-Water Flow in Hydraulic Structures. USBR Engineering Monograph No. 41. Washington, DC: United States Department of the Interior, Water and Power Resources Service. http://www.arlis.org/docs/vol2/hydropower/APA_DOC_ no._899.pdf.

Koe, L. and D. Brady. 1986. "Olfactory Quantification of Sewer Odours." Journal of Environmental Engineering 112 (12): 311-27.

Koziel, J. A, R. L. Corsi and D. F. Lawler. 2001. “Gas-Liquid Mass Transfer Along Small Sewer Reaches." Journal of Environmental Engineering 127 (5): 430-7.

Lautenbach, D. J., P. Klaver, J. G. Vasconcelos. and S. J. Wright. 2012. “Numerical and Experimental Analysis of Surge, Transient and Trapped Air Phenomena in Two Large Wastewater Storage Tunnels." In North American Tunneling 2012 Proceedings, edited by M. Fowler, R. Palermo, R. Pintabona and M. Smithson Jr. Englewood, CO: Society for Mining, Metallurgy and Exploration Inc (SME).

Lowe, S. A. 2016. "Sewer Ventilation: Factors Affecting Airflow and Modeling Approaches." Journal of Water Management Modeling C395. https://doi.org/10.14796/JWMM.C395.

Parker, W. J. and H. Ryan. 2001. "A Tracer Study of Headspace Ventilation in a Collector Sewer." Journal of the Air \& Waste Management Association 51 (4): 582-92.

Pescod, M. B. and Price, A. C. (1982) "Major factors in sewer ventilation." Journal of the Water Pollution Control Federation 54 (4): 385-97. 
Quigley, C. J. and R. L. Corsi. 1995. "Emissions of VOCs from a

Municipal Sewer." Journal of the Air \& Waste Management Association 45 (5): 395-403.

Reid, G. W. and C. Imel. 1956. "Sewer Odour Studies." Sewage and Industrial Wastes 28 (8): 991-7.

Schultz, N., D. Nero, S. Matthews-Rohadfox and E. L. Glover. 2012. "Lessons Learned from Operating Large Sewage Tunnels." Proceedings of the Water Environment Federation, Collection Systems 2012, WEF, Alexandria, VA.

Sydney, R., E. Esfandi and S. Surapaneni. 1996. “Control Concrete
Sewer Corrosion via the Crown Spray Process." Water Environment Research 68 (3): 338-47.

WERF (Water Environment \& Reuse Foundation/Water Environmental Research Foundation). 2009. Collection System Ventilation Research Report. Alexandria, VA: Water Environmental Research Foundation (now Water Environment \& Reuse Foundation). Report 04-CTS-1a.

Yongsiri, C., J. Vollertsen and T. Hvitved-Jacobsen. 2004. “Effect of Temperature on Air-Water Transfer of Hydrogen Sulfide." Journal of Environmental Engineering 130 (1): 104-9. 